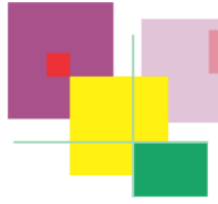

DOI: 10.20396/lil.v46i46.8661634

\title{
REPRESENTAÇÕES SOBRE CIÊNCIA E CIENTISTA EM POKEMON E LILO \& STITCH
}

\section{REPRESENTATIONS ON SCIENCE AND SCIENTIST IN POKEMON AND LILO \& STITCH}

\author{
Ilka de Oliveira Mota* \\ UFSCar \\ Yuri de Oliveira Monteiro Nobre** \\ UFSCar
}

Resumo: Este trabalho tem por objetivo compreender as representações imaginárias sobre ciência e cientista que atravessam dois desenhos infantis estrangeiros que circulam na TV brasileira: Pokemon e Lilo \& Stitch. Para isso, apoiamo-nos no aparato teórico-metodológico da Análise de Discurso de linha francesa e brasileira, mobilizando noções como texto, discurso, imaginário e formação discursiva. Partimos do pressuposto de que os desenhos animados, longe de serem objetos inocentes e transparentes, trazem em seu bojo regiões de interpretação a partir das quais irrompem diferentes discursividades, reforçando muitas vezes sentidos cristalizados sobre relações sociais, ciência e cientista.

Palavras-chave: Ciência, Imaginário, Desenho animado.

Abstract: The work aims at understanding the imaginary representations about science and scientist that cross two foreign cartoons that circulate in Brazilian TV: Pokemon e Lilo \& Stitch. For this end, it relies on the theoretical-methodological apparatus of Discourse Analysis of French and Brazilian lines, mobilizing notions such as text, discourse, imaginary and discursive formation. We assume that cartoons, far from being innocent and transparent objects, are regions of interpretation from which different discursivities break out, reinforcing crystallized meanings about social relations, science and scientist.

Keywords: Science, Imaginary, Cartoon. 


\section{Introdução}

Neste trabalho, analisamos os desenhos animados Pokemon e Lilo \& Stitch a fim de compreender os modos de representação imaginária sobre ciência e cientista que os atravessam. Para isso, apoiamo-nos no aparato teórico-metodológico da Análise de Discurso de cunho materialista, mobilizando noções como texto, discurso, imaginário e formação discursiva.

Para situar o leitor em relação à metodologia adotada, os recortes aqui analisados foram extraídos dos aludidos desenhos animados e, para cada um, selecionamos um episódio que julgamos exemplificador, enquanto regularidade, do funcionamento discursivo que comparece neles. Trata-se de desenhos estrangeiros que têm circulação na televisão brasileira (fechada e aberta) com audiência expressiva. Interessa-nos especialmente compreender as representações imaginárias, a partir da materialidade linguística e imagética conjuntamente, sobre ciência e cientista que constituem $\mathrm{o}(\mathrm{s})$ sujeito(s) das diferentes práticas linguageiras que circulam na mídia televisiva.

No cinema americano do século XX, encontramos personagens cientistas que se tornaram famosos, tais como: Dr. Frankenstein, Dr. Jekyll, Dr. Moreau, Dr. Strangelove. Todos eles reforçam a ideia de um cientista excêntrico, solitário e com inteligência acima da média de nós, reles mortais! Isto é, o cientista é apresentado, imaginariamente, como detentor de um caráter genial, bem superior às demais pessoas da vida ordinária.

Ao lado dos filmes norte-americanos, em grande parte das propagandas publicitárias, também deparamo-nos com a presença recorrente da figura da ciência e do cientista. Este geralmente comparece como homem, branco, travestido de óculos e um jaleco em um laboratório de química, já aquela comparece sob o rótulo do estritamente experimental. Trata-se daquilo que Perez et al. (2001) denominam de concepção empírico-indutivista. Para os autores essa seria uma das sete visões deturpadas sobre ciência que estão fortemente cristalizadas no imaginário social e bastante propagadas pela mídia televisiva principalmente. No caso específico dessa visão, tudo se passa como se a experimentação e a observação fossem a única forma de produção do conhecimento científico ${ }^{1}$, o que leva a pensar que aquilo que não é experimental não é ciência. Daí a presença maciça de 
laboratórios - em especial os de química - nas animações direcionadas ao púbico infantil.

Um dos motivos que nos motiva a empreender a presente pesquisa diz respeito à grande quantidade de desenhos infantis que trazem à baila o tema da ciência e seus protagonistas cientistas, geralmente homens e brancos. Esses dois últimos aspectos - gênero e raça - têm a ver com o que Perez et al. (2001, p. 133) denominam visão elitista da ciência, que consiste, entre outras coisas, "[...] em que o trabalho científico é um domínio reservado a minorias especialmente dotadas, transmitindo-se assim expectativas negativas à maioria dos alunos, com claras discriminações de natureza social e sexual (a ciência é apresentada como uma atividade eminentemente "masculina")". Só recentemente, temos assistido a uma suposta mudança nesse modo de representação do gênero no âmbito da ciência: a mulher tem sido colocada para dentro da cena discursiva, o que tem suscitado trabalhos significativos, nas Ciências Humanas e Sociais, para compreender o modo de significação da mulher e seus possíveis efeitos de sentido.

Recorrentes no cotidiano do público infantil, os desenhos animados exercem uma poderosa influência no processo identitário da criança, produzindo efeitos importantes no imaginário, sendo este compreendido como espaço de organização dos sentidos. Nosso objetivo é, parafraseando Orlandi (1999, p. 42), atravessar o imaginário a fim de compreender o modo como os sentidos estão sendo produzidos. Para isso, é necessário referir a materialidade linguístico-imagética às suas condições de produção, estabelecer as relações que ela mantém com sua memória e também remetê-la a uma formação discursiva - e não outra - para compreendermos o processo discursivo implicado.

\section{Desenhos animados: uma abordagem discursiva}

Faz-se necessário pensar discursivamente no funcionamento da materialidade cartoon (desenho animado) para compreender os processos discursivos que se instauram na produção de sentidos para ciência e cientista. Portanto, nosso objetivo não é trazer o histórico dos desenhos animados, mas compreender o modo como significam e representam a figura da ciência e do cientista na contemporaneidade.

A respeito de sua especificidade, importa dizer que a característica fundamental que marca a materialidade cartoon é a ludicidade, a 
brincadeira e, por vezes, o humor. Aqui referimo-nos especialmente aos desenhos animados que têm o público infantil projetado.

Vale dizer que o fato de ser lúdico não significa que o desenho animado seja fruto de uma imaginação ingênua, sem ideologia, sem compromisso com os sentidos e com a história, tal como comparece no imaginário social em geral. Noutros termos, longe de ser uma "mera brincadeira" sem consequência para a subjetividade e para o processo de identificação do sujeito, o desenho animado implica relações subjetivas, sociais e culturais importantes que se mostram profícuos para o analista de discurso.

Outra característica importante dos cartoons é a sua configuração textual. Caracterizado pelos planos verbal e não verbal, o desenho animado comparece como um texto, à medida que está intimamente relacionado com a exterioridade, isto é, com o contexto sócio-histórico e ideológico em que é produzido.

Expliquemos. Discursivamente, concebemos o desenho animado como um tipo de texto que se caracteriza pelo jogo entre os planos verbal e não verbal, o que rompe, a nosso ver, com a ideia hegemônica de texto como um conjunto de palavras organizadas. Acrescente-se, os desenhos apresentam um fio narrativo permeado por uma pequena história que envolve personagens, enredo e outros elementos característicos do gênero narrativo. Para reiterar, o conteúdo que trazem, no caso dos desenhos endereçados ao público infantil, tende ao lúdico, à brincadeira e, alguns deles, ao humor.

Como todo e qualquer texto, isto é, como unidade de significação, o desenho animado é uma materialidade a partir da qual diferentes discursividades o atravessam, produzindo efeitos de sentido que podem atuar de modo consequente no imaginário social. A partir da análise desse material (desenhos animados), é possível compreender como os sentidos são produzidos, bem como as representações imaginárias sobre "cientista" e "ciência" na história.

Em síntese, o desenho animado é, para nós, uma prática linguageira que, portanto, não está apartada da ordem do social e da história.

A respeito da metodologia, importa fazer algumas considerações que julgamos importantes. A presente pesquisa foi produzida com base em uma investigação interpretativista. Segundo Coracini (2003, p. 254), nesse tipo de pesquisa, "o pesquisador interpreta os dados, põe ênfase 
no processo e se preocupa com o particular, o contingente". Ou seja, o olhar do pesquisador sobre o objeto de pesquisa se constitui sempre e necessariamente em um gesto, o que equivale a dizer que é um ato no nível do simbólico (PECHEUX, 1969).

Discursivamente, não há sentido sem interpretação, já que, diante de qualquer objeto simbólico, somos, enquanto sujeitos histórica e socialmente constituídos, levados a interpretar, como bem afirma Orlandi (1999, p. 45). Isso se dá porque o sujeito se submete à língua(gem) - mergulhado em sua experiência de mundo e determinado pela injunção a dar sentido - em um gesto, um movimento sócio e historicamente situado. Por seu lado, o pesquisador, situado em um aparato teórico-metodológico específico, faz um gesto que se distingue do gesto ordinário do sujeito que tem em sua base o efeito do apagamento da exterioridade, com a ilusão do sentido-já-lá, de sua evidência. Ao procurar compreender como os sentidos são produzidos, o pesquisador está, ao mesmo tempo, recusando a ilusão da evidência dos sentidos e dos sujeitos, levando em conta, entre outros, os gestos de interpretação, a alteridade, o sentido outro, a historicidade. Em resumo, interpretar, para o analista de discurso, não é simplesmente atribuir sentidos, mas expor-se à opacidade do texto (PÊCHEUX, 1983 [1990]).

Concebemos a linguagem como aquela que remete a sua exterioridade, às relações do sujeito com o discurso, o que nos permite compreender o funcionamento discursivo. Funcionamento já que se trata de uma atividade estruturante de um discurso determinado, por um falante determinado, para um interlocutor determinado, com finalidades específicas e não de um modelo que o sujeito procura preencher (ORLANDI, 1983).

Uma vez que o nosso trabalho se constitui em gestos de interpretação, é preciso adotar um dispositivo de análise que se diferencie do gesto de interpretação do sujeito comum, isto é, tomado pela evidência dos sentidos. O dispositivo analítico objetiva: a) explicitar os gestos de interpretação que se ligam aos processos de identificação do sujeito; b) explicitar suas filiações de sentido; c) compreender a linguagem em sua opacidade; d) relacionar o(s) sentido(s) à exterioridade e, finalmente, e) relacionar o dito ao não dito.

A interpretação aparece em dois momentos da análise, momentos que não devem ser concebidos separadamente, mas em um jogo de 
relações. Primeiramente, assumimos que a interpretação faz parte do objeto de análise, isto é, sempre interpretamos (afinal, não há como estar fora da interpretação, como já comentamos) e procuramos descrever esse gesto de interpretação que constitui o sentido submetido à análise. Em um segundo momento, compreendemos que não há descrição sem interpretação. Daí ser necessária a adoção de um dispositivo teórico que intervenha na relação do pesquisador com os objetos simbólicos que analisa, produzindo, necessariamente, um deslocamento em sua relação de sujeito com a interpretação: é esse deslocamento que vai permitir que ele trabalhe no entremeio da descrição com a interpretação (ORLANDI, 1999).

Tal como já comentado, investigamos dois desenhos animados infantis - Pokémon e Lilo \& Stitch-que, embora estrangeiros, circulam na mídia televisiva brasileira. Por serem heterógenas por excelência, tais animações permitiram-nos compreender as imagens historicamente construídas para Ciência e cientista atreladas a uma memória discursiva.

Para aquilo que nos interessa nesse trabalho, importa dizer quão importante é a noção de recorte discursivo, uma vez que ela nos permite considerar, no processo de compreensão dos sentidos, a situação de interlocução, tal como Orlandi (1984, p. 14) assevera: "os recortes são feitos na (e pela) situação de interlocução, aí compreendido um contexto (de interlocução) menos imediato: o da ideologia". Esta é compreendida como mecanismo de produção de evidência do sujeito e dos sentidos. Ao produzir evidências, ela coloca o homem na relação imaginária com suas condições materiais de existência. Em uma palavra: ela é condição para a constituição dos sujeitos e dos sentidos.

Assim, o que se recorta extrapola um conjunto de formulações linguísticas, demandando um esforço de compreensão de determinadas relações textuais incidentes em um contexto de interlocução, relações entre textos realizados numa cadeia significante recuperável por amostragem imagética, escrita ou sonora, e textos não realizados nessa cadeia, mas evocados no acontecimento histórico de sua significação e interpretação. Esses outros textos, não realizados na cadeia significante, constituem-se como as próprias condições de produção de um discurso. No caso específico de materialidades significantes não linguísticas (não-verbais, verbo-visuais etc., como a nossa), é importante que o 
recorte não implique segmentação dos elementos visuais, uma vez que na Análise de Discurso a cadeia significante interessa mais do que os signos que a compõem (LAGAZZI, 2009).

De nossa parte, há algumas noções teóricas basilares na compreensão do discurso e que serão muito produtivos no processo de análise. Uma delas é o mecanismo de antecipação que funciona pelo imaginário. Tal mecanismo, constitutivo do funcionamento da linguagem, consiste no fato de que todo sujeito experimenta, ainda que inconscientemente, o lugar de seu interlocutor, regulando a formulação de tal maneira que enunciará de um modo ou de o outro, de acordo com o efeito que imagina (espera) produzir.

Já a outra noção teórica é o de relação de forças. Essa noção permite compreender que o lugar a partir do qual o sujeito enuncia é constitutivo de seu dizer. Considerando o modo de organização de nossa sociedade, perpassada, como sabemos, por mecanismos de poder, a fala de um sujeito pode valer mais que a fala de outros numa escala hierárquica. Tudo vai depender das determinações históricas que atravessam o lugar de onde o sujeito $(\mathrm{x}, \mathrm{y}, \mathrm{z})$ enuncia.

Por fim, a noção de formação discursiva é fundamental para ser mobilizada na análise. Ela se define como aquilo que numa formação ideológica dada - isto é, a partir de uma posição dada em uma conjuntura sócio-histórica dada - determina o que pode e deve ser dito.

\section{Resultados e discussão}

A partir da análise dos desenhos animados selecionados, observamos similaridades e diferenças importantes entre as materialidades analisadas. Porém, antes de discorrermos sobre elas, delinearemos as condições de produção de cada uma, o que indicará, implicitamente, as diferenças que os caracterizam para, na sequência, trazermos os resultados da análise e a sua discussão.

\subsection{Lilo \& Stitch}

O desenho animado Lilo \& Stitch traz como protagonista a garotinha havaiana Lilo, que tem 5 anos e passa grande parte de seu tempo nas mais diferentes aventuras sozinha, o que acaba afastando de si outras garotas de sua idade. Segundo a narrativa fílmica, seus pais sofreram um acidente quando era um bebê, motivo pelo qual passou a morar com sua irmã Nani. Até então seu único amigo era Fofuxo, um peixe que ela 
alimenta todos os dias com um sanduíche de pasta de amendoim. Em um de seus momentos de solidão, assim que Lilo roga a Deus um amigo de verdade, aparece Stitch, que muda completamente seu destino.

Stitch é um alienígena que, ao cair do céu e ter sua nave destruída, fica preso à Terra. Conforme conta a história, numa "certa" manhã Lilo e Nani vão até um abrigo de animais adotar um cãozinho para ser o companheiro de Lilo, porém, ela acaba, por engano, adotando o extraterrestre Stitch. Na condição de alien fugitivo de outro planeta, Stitch tem que se esconder, utilizando-se, para isso, um disfarce de cão e fugir da polícia galáctica sob a guarda de Lilo. Stitch, que fora projetado inicialmente para destruição, depara-se com o amor e carinho da garotinha, tornando-se amigos inseparáveis. Até o cientista gênio do mal, Jumba Juquiba, criador de Stitch e um de seus perseguidores na trama, torna-se parte da família quando todo o desfecho do filme acontece. A seguir, o leitor pode vislumbrar a figura de Lilo e Stitch:

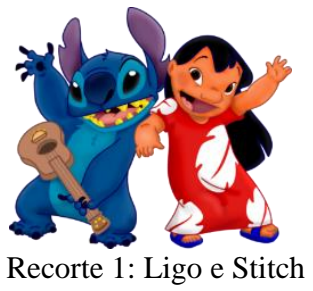

\subsubsection{Pokemòn e Lilo \& Stitch}

O título do desenho animado Pokémon é uma abreviação da expressão em inglês "Pocket Monsters", que significa "monstros de bolso". Trata-se de um universo semelhante ao nosso, porém, ao invés de animais, existem pokémons: animais considerados incríveis com habilidades extraordinárias. Ash, um jovem garoto, começa sua jornada Pokémon a fim de capturar todos os pokémons existentes com o objetivo de se tornar um grande treinador de pokémons sob a orientação do cientista Professor Carvalho. Na animação, o cientista é significado como autoridade suprema quando o assunto é pokémons. O cientistaprofessor confere ao garoto tudo que será necessário para sua aventura: todos os equipamentos e parafernálias e seu primeiro companheiro Pokémon. 
A história traz as aventuras de Ash capturando e batalhando com pokémons de regiões diferentes, posteriormente os envia para o professor por meio de máquinas futurísticas avançadas.

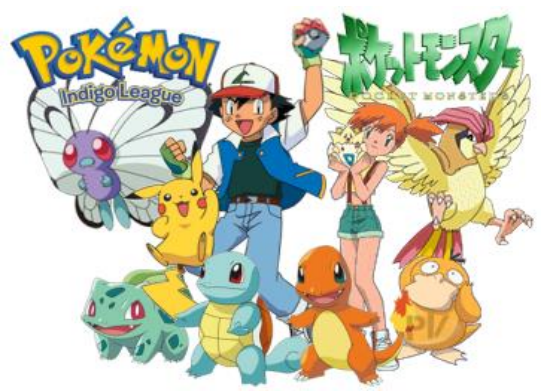

Recorte 2: Ash e seus amigos Pokémons

\subsection{Similaridades e diferenças: Lilo \& Stitch e Pokémon}

Em Lilo \& Stitch, Jumba Jookiba é um alienígena, isto é, não tem nenhuma ligação com o Planeta Terra. No plano imagético, ele é apresentado como um ser com a seguinte aparência: gordo, alto, tem quatro olhos, louco e fala uma língua muito diferente dos demais personagens da narrativa fílmica. Representado como cientista, ele realiza experimentos ilegais sem a aprovação do Governo e ocupa um cargo na defesa galáctica do universo. Imaginariamente, é representado, no plano do imaginário, como um gênio do mal, isto é, ele comparece como um personagem pertencente ao paradigma do mal. Observemos o recorte que segue:

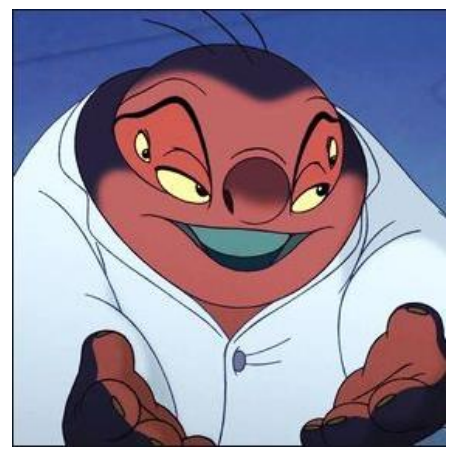


Por seu lado, no desenho Pokémon, o personagem Professor Carvalho é um cientista representado imaginariamente (no plano visual e psicológico) a partir das seguintes características: homem alto, magro, de cabelos grisalhos, centrado, sério (geralmente aparece com a testa franzida) e trajando um jaleco branco. Na textualidade fílmica, Carvalho comparece solitário na maior parte dos episódios: trancado em seu laboratório, que se confunde, em algumas passagens, com a sua casa, aparece fazendo sua refeição, o que é um gesto que rompe o código de ética que rege as boas maneiras em um laboratório.

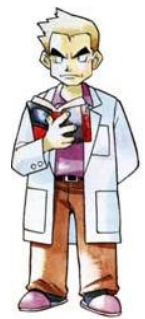

Recorte 4: Professor Carvalho (cientista)

Vale dizer ainda que ambos os personagens, representados como cientistas, têm laboratórios e trabalham sozinhos. A diferença está em que, no caso do professor Carvalho, ele precisa (depende) de treinadores (humanos) para reunir dados referentes aos pokémons. A interlocução entre eles se dá pela via tecnológica (telefone e computador), tal como os recortes abaixo bem evidenciam. A formação discursiva tecnológica embasa toda a narrativa fílmica: telefone, celular, computador e conversa online síncrona: 

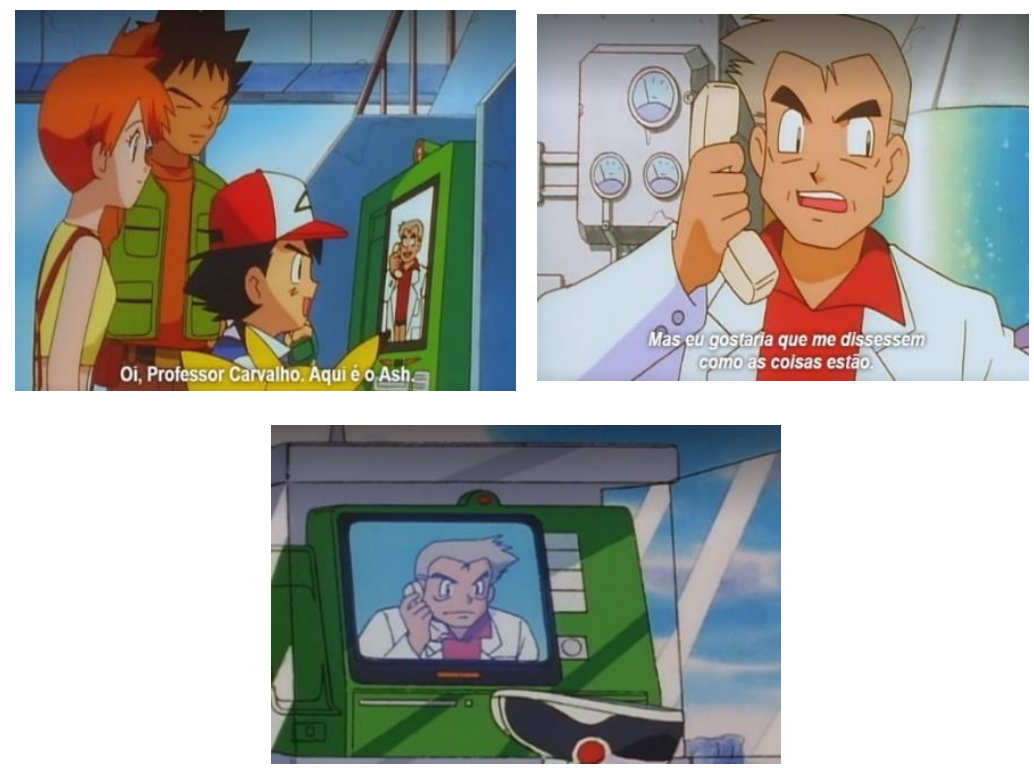

Recorte 5: Professor Carvalho em seu laboratório e seus treinadores

A cena acima foi retirada de um dos episódios do filme Pokemon, que, por ser bastante regular, é emblemática do modo de representação do cientista e da ciência. A textualidade vai se compondo marcada por sucessivos diálogos entre, o Professor Carvalho, que aparece trancafiado em seu laboratório, e seus treinadores. A distância geográfica entre os personagens - treinadores e cientista - corrobora a memória discursiva sobre ciência como aquela inacessível, aparatada da sociedade, já que, na maioria das cenas, o professor aparece sozinho em seu laboratório, isto é, sem a presença de humanos. Esse gesto de interpretação prende o público nessa textualidade, reforçando sentidos para a ciência e aqueles que nela atuam.

A seguir, o recorte 6 traz uma cena em que Ash, futuro treinador de Pokémon, se dirige ao Centro de Pesquisas Pokémon, coordenado pelo professor Carvalho, para lhe dizer que está preparado para iniciar a sua jornada como treinador. O cientista ri e, olhando a roupa de Ash, 
comenta em tom de deboche: “_Você não está preparado para uma aventura Pokémon, você está preparado para ir para a cama!”:

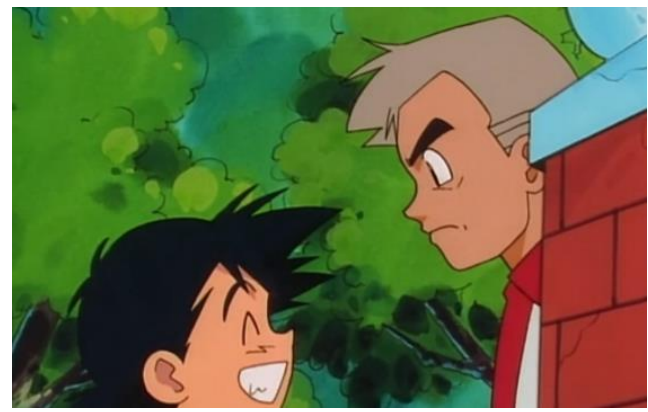

Recorte 6: Ash e Professor Carvalho conversando

O recorte traz uma cena de plano médio, conhecido, na linguagem cinematográfica, como medium shot: a câmera está a uma distância média do objeto. Trata-se de um plano de posicionamento e movimentação. No caso, a câmera registra a relação entre os personagens e suas expressões faciais: o professor Carvalho, cientista, aparece com uma expressão raivosa e o menino com uma risada sem graça. O riso de Ash, diferentemente do riso debochado do professor Carvalho que antecede o aludido quadro, é produzido em razão da posição inferior na qual o cientista o coloca. Temos aí, no plano verbovisual, aquilo que em Análise de Discurso é chamado de relações de força que, reiterando, consiste na consideração do fato de que o lugar a partir do qual o sujeito enuncia é constitutivo do que ele diz. Em síntese, no presente recorte, vemos materializadas as relações de força entre o professor, que enuncia a partir do discurso da ciência, e Ash, um treinador. Nas palavras de Orlandi (1999, p. 39), "Como nossa sociedade é constituída por relações de força hierarquizadas, são relações de força, sustentadas no poder desses diferentes lugares, que fazem valer na "comunicação"". Na referida cena fílmica, a fala do professor Carvalho, inscrita na ordem do discurso científico, significa (vale) mais do que a do treinador.

A cena seguinte traz um deslize importante produzido pelo registro (inusitado?) de uma violação de um código de ética que orienta o trabalho em laboratório: ao mesmo tempo em que Carvalho trabalha em 
seu laboratório, prepara a sua refeição na bancada em que faz experimentos químicos. Discursivamente, pode-se dizer que estamos diante de um furo na ordem do discurso da ciência que não prevê preparação de refeição e seu consumo em um laboratório químico. Trata-se de um deslize que abala as redes de filiação histórica que representam a ciência e o cientista no lugar da superioridade, perfeição e não contradição. Observemos:

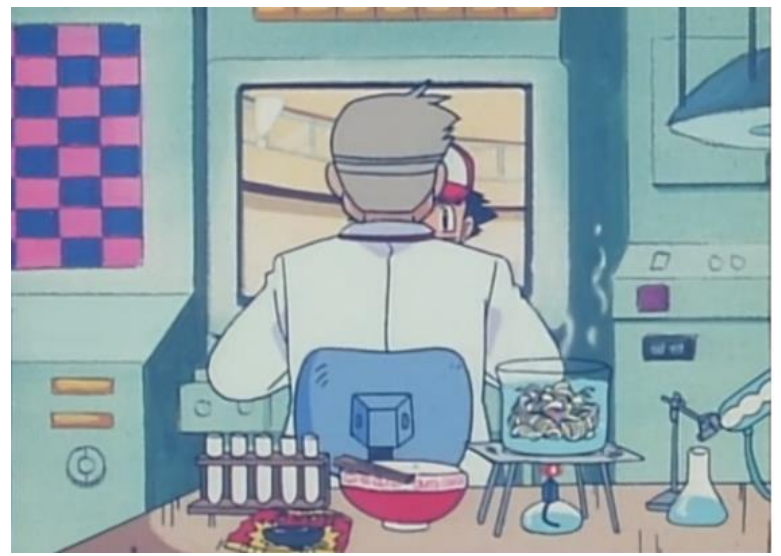

Recorte 7: Experimentos químicos mesclados à preparação de refeição.

Conhecido como um profissional competente, preocupado e extremamente estressado em virtude da quantidade de trabalho, o professor Carvalho comete uma infração: no laboratório em que faz vários experimentos químicos, é flagrado preparando a sua refeição.

Uma equivocidade irrompe no fio da narrativa fílmica: o cientista não é tão perfeito quanto quer o desenho em sua totalidade. O equívoco que a cena traz aponta para o fato de que a ciência é humana demasiadamente humana, parafraseando Nietzsche! -, ou seja, ela também é constituída de falhas e contradições. O lúdico aí aponta para a falta, a incompletude, isto é, para o fato de que o sentido não se fecha, pois é uma questão filosófica, como diria Henry (1981).

Acrescente-se, para que Ash não flagre a bancada com as parafernálias culinárias, o Professor, assustado e tenso, muda de câmera rapidamente, para despistar, esconder a infração cometida do aprendiz. Mas, ironicamente, o fato inusitado é que ele não consegue esconder o 
ato do público que assiste à contradição instaurada na textualidade fílmica. A imagem de profissional perfeito desabafa, pouco a pouco, diante do olhar do público. A materialidade verbo-visual funciona ideologicamente, trazendo em seu bojo esse jogo, o lugar da falha, do equívoco.

Do recorte 8 que segue abaixo vê-se o laboratório de Jumba Zookiba no formato de um asteroide ao som de uma música instrumental de denota suspense. O primeiro quadro mostra o interior do laboratório, já o segundo, o seu exterior.
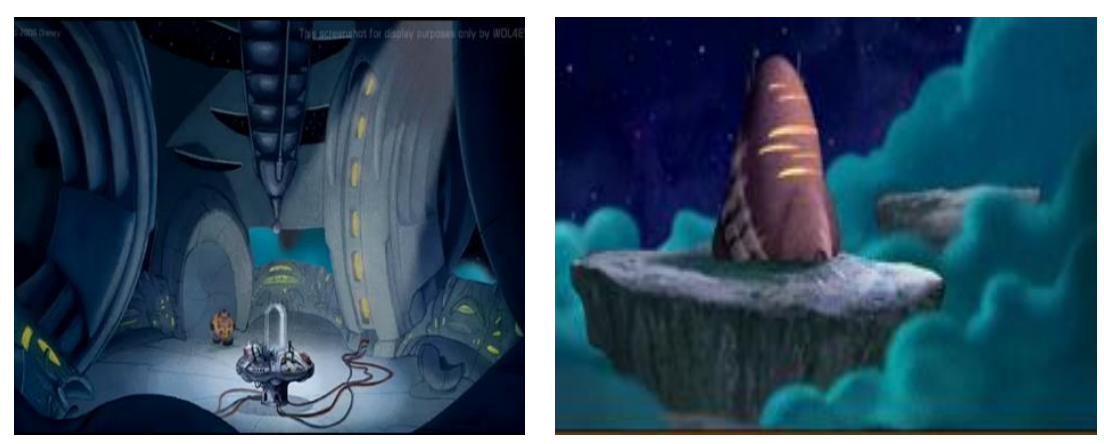

Recorte 8: Jumba Zookiba e seu laboratório

O recorte 8 traz uma cena bastante regular na animação de Lilo \& Stich: o laboratório do cientista Jumba é retratado por meio de um mecanismo fílmico que produz, enquanto efeito de sentido, um distanciamento entre aquele que assiste (o público) e o personagem cientista Zumba e seu laboratório metaforizado na figura de um asteroide. Esse efeito é produzido pelo recurso fílmico do zoom out que consiste em afastar, distanciar um dado objeto. Na cena em que mostra tanto o interior do laboratório (quadro 1, recorte 8), quanto o seu exterior (quadro 2, recorte 8), há um efeito de afastamento que, discursivamente, é sintoma do modo como ciência e cientista são representados. Isso mostra como o imaginário faz parte necessariamente do funcionamento da linguagem (ORLANDI, 1999, p. 42).

Do ponto de vista do discurso, esse modo de enquadramento fílmico (zoom out) - que é um modo de interpretar o laboratório a partir de uma 
certa memória discursiva - inscreve-se em uma região de sentidos que significa a ciência e o cientista de um modo determinado. Noutros termos, ao afastar o objeto (laboratório) do público, o zoom out delimita a quem o laboratório (ciência) pertence e a quem ele não pertence, quem a ele tem e não tem acesso, legitimando, na textualidade, a divisão opositiva ciência/senso comum, cientistas/reles mortais.

Como já afirmamos, tanto Jumba Zookiba quanto o Professor Carvalho são cientistas e proprietários dos laboratórios nos quais trabalham e moram, laboratórios aos quais as pessoas não têm acesso, principalmente no caso de Jumba. Sem que haja acesso a outras pessoas e/ou seres, os laboratórios comparecem como uma espécie de local divino, sagrado, aos quais poucos ou ninguém pode ter acesso ${ }^{2}$.

O laboratório do cientista Zookiba é retratado como um asteroide vagando no espaço, já o do professor Carvalho está localizado em uma colina com portões altos ao entorno. Nesse modo de significação ficam evidentes as imagens construídas historicamente sobre ciência e o cientista veiculadas pelas referidas animações: tudo se passa, imaginariamente, como se a ciência estivesse distante das pessoas, da sociedade, e o cientista fosse um Deus, uma pessoa iluminada, dotada de uma inteligência superior à média. Sendo atualização da memória discursiva, a formulação (em nosso caso, produzida verbo-visualmente) se faz materialmente pela colocação do discurso da ciência em texto, pela textualização.

Tudo isso nos leva a afirmar que todo dizer se faz em um ponto em que atravessa o interdiscurso: é a partir dele que o sujeito significa, enuncia e é ele também que costura a tessitura da materialidade fílmica de uma forma determinada historicamente.

A diferença entre Jumba Zookiba e o professor Carvalho está principalmente no modo de significação (caracterização imagética e de personalidade). Para sistematizar as diferenças mais marcantes, criamos o quadro a seguir que sintetiza as regularidades levantadas no processo de análise empreendida: 


\begin{tabular}{|l|c|c|}
\hline \multicolumn{3}{|c|}{ QUADRO PARADIGMÁTICO } \\
\hline \multirow{4}{*}{ DIFERENÇAS ENTRE OS PERSONAGENS CIENTISTAS } \\
\hline \multirow{4}{*}{$\begin{array}{l}\text { Personagens } \\
\text { cientistas }\end{array}$} & Professor Carvalho & Jumba Zookiba \\
\cline { 2 - 3 } & Humano (homem) & Alienígena \\
\cline { 2 - 3 } & $\begin{array}{c}\text { Alto, loiro, branco, magro, } \\
\text { sério }\end{array}$ & $\begin{array}{c}\text { Baixo, disforme (4 } \\
\text { olhos), gordo }\end{array}$ \\
\cline { 2 - 3 } & $\begin{array}{c}\text { Interlocução com os } \\
\text { treinadores de pokémons, } \\
\text { ainda que pela via do } \\
\text { computador e telefone }\end{array}$ & $\begin{array}{c}\text { Nenhuma } \\
\text { interlocução, } \\
\text { trabalha estritamente } \\
\text { sozinho }\end{array}$ \\
\cline { 2 - 3 } & Retrato como gênio do Bem & $\begin{array}{c}\text { Retrato com gênio } \\
\text { do Mal }\end{array}$ \\
\hline
\end{tabular}

Já as semelhanças, que são bastantes, seguem dispostas no quadro paradigmático abaixo proposto:

\begin{tabular}{|c|c|}
\hline \multicolumn{2}{|c|}{$\begin{array}{c}\text { QUADRO PARADIGMÁTICO } \\
\text { SEMELHANÇAS ENTRE OS PERSONAGENS CIENTISTAS }\end{array}$} \\
\hline Personagens cientistas & Semelhanças \\
\hline $\begin{array}{l}\text { Professor Carvalho (Animação: } \\
\text { Pokémon) }\end{array}$ & $\begin{array}{l}\text { a) Rompem o código de ética: } \\
\text { Carvalho faz sua refeição no } \\
\text { próprio laboratório, enquanto } \\
\text { Jookiba realiza experimentos } \\
\text { considerados ilegais no campo da }\end{array}$ \\
\hline $\begin{array}{l}\text { Jumba Jookiba (Animação: Lilo } \\
\text { \& Stitch) }\end{array}$ & $\begin{array}{l}\text { Ciência. } \\
\text { b) Trabalham sozinhos (solitários) } \\
\text { e residem em seus laboratórios. } \\
\text { No caso do Professor Carvalho, } \\
\text { embora só ele trabalhe em } \\
\text { laboratório, ele depende dos } \\
\text { treinadores para reunir dados } \\
\text { referentes aos pokémons, } \\
\text { enquanto Jookiba trabalha } \\
\text { estritamente sozinho, isto é, seu } \\
\text { trabalho científico é feito sem } \\
\text { nenhum contato com outrem. } \\
\text { c) Pertencem ao gênero } \\
\text { masculino. }\end{array}$ \\
\hline
\end{tabular}




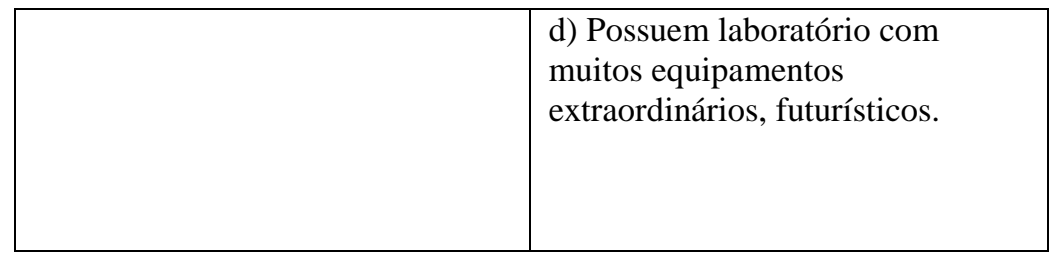

Antes de passarmos para as conclusões, resta dizer, como apontado no quadro acima, que em ambos os desenhos aquele que exerce o ofício da Ciência tem um gênero, o masculino. Trata-se, de nossa parte, de um discurso de ciência que traz em seu bojo uma memória patriarcal, memória essa cristalizada que precisa, a nosso ver, ser debatida e, por que não dizer, combatida (desconstruída) seja no contexto escolar, seja na sociedade em geral, já que estamos em uma sociedade heterogênea em que há diferentes modos de ser sujeito na história.

Outra regularidade marcante capturada pela escuta analítica é a imagem do cientista trancafiado (encarcerado?) solitariamente em um laboratório, envolto de parafernálias, tais como tubos de ensaio, equipamentos altamente tecnológicos etc. Discursivamente, permeia aí uma visão individualista da ciência a partir da qual, segundo Perez et al. (2001), "os conhecimentos científicos aparecem como obras de gênios isolados, ignorando-se o papel do trabalho coletivo e cooperativo, dos intercâmbios entre equipes". Dito de outro modo, temos aí o apagamento de um aspecto importante do trabalho científico: o caráter coletivo das pesquisas.

Na mesma direção de sentidos, a ciência é representada, no plano do imaginário, como exótica, complexa e dissociada da sociedade. Não é à toa que o cientista geralmente comparece em cena fazendo experimentos em um laboratório, sendo este significado imaginariamente como algo fora história, isto é, das condições de produção em que ela (a ciência) é produzida. Tudo se passa como se houvesse uma separação entre ciência, de um lado, e sociedade, do outro, o que resulta em um apagamento do caráter sócio-histórico e ideológico constitutivo do fazer científico.

Levando em consideração todos esses aspectos observados na análise, pode-se dizer que a hipótese de trabalho se confirma: longe de serem objetos inocentes, neutros e transparentes, os desenhos animados analisados materializam processos sociais importantes que representam 
a ciência e o cientista pelo menos a partir da região de sentidos que segue: a) a ciência é algo distante dos reles mortais, sendo acessível somente àqueles que apresentam superdotação intelectual, isto é, capacidade mental acima da média, promovendo uma distância entre ela e os sujeitos da vida ordinária; b) os cientistas, de sexo masculino, trabalham sozinhos, cada qual em seu laboratório, o que incute a ideia de que a ciência está apartada do social e da história e, finalmente, c) as animações em questão reforçam uma imagem de ciência positivista, que se desenvolve a partir de problemas e está associada à atividade experimental. É sempre um problema que motiva a ação científica que vai conduzir a história.

\section{Considerações finais}

Neste trabalho, procuramos compreender as representações imaginárias sobre ciência e cientista que atravessam dois desenhos infantis estrangeiros, Pokemon e Lilo \& Stitch. Para isso, apoiamo-nos no aparato teórico-metodológico da Análise de Discurso de linha francesa e brasileira, mobilizando noções como texto, discurso, imaginário e formação discursiva. Partimos do pressuposto de que os desenhos animados, longe de serem objetos inocentes e transparentes, trazem em seu bojo regiões de interpretação a partir das quais irrompem diferentes discursividades, reforçando muitas vezes sentidos cristalizados sobre relações sociais que engendram ciência e cientista.

No modo de representação da ciência e, por conseguinte, do cientista, vemos um apagamento do real histórico, mais exatamente, veicula-se uma imagem de ciência inquestionavelmente boa - resolve problemas, salva o planeta, traz o progresso (cabe aqui a pergunta: que progresso? para quem?).

Paradoxalmente, deparamo-nos com uma imagem de ciência com furos, tal como a cena em que aparece o Professor Carvalho deixar ver: experimento e refeição são preparados no interior de seu laboratório científico. São expostas aí contradições que abalam, como já afirmamos, a ordem do discurso científico. Noutros termos, trata-se da justificação de ações antiéticas: de um lado, temos a quebra do código de ética pelo professor Carvalho que faz sua refeição no próprio laboratório e, de outro, Jumba Jookiba realiza experimentos considerados ilegais pela comunidade científica, tais como 
experimentações com DNA de seres vivos, misturando esse material genético com outras substâncias a fim de criar monstros.

Pesquisar os referidos desenhos animados foi importante à medida que permitiu compreender o modo como a mídia televisiva, enquanto aparelho ideológico de Estado, significa e tem significado as figuras do(a) cientista e da ciência e, de outro lado, desconstruir uma certa imagem do desenho animado como um material ingênuo, sem consequências para a subjetividade dos sujeitos na contemporaneidade.

De nossa parte, seria importante um deslocamento nas redes de filiações históricas a fim de que a ciência e a figura do cientista possam ser significados de outros modos. Ou seja, deslocar os sentidos para outros lugares de significação, fazendo emergir o irrealizado, o que ainda não significou.

\section{Referências bibliográficas}

CORACINI, M. J. R. F. O olhar da ciência e a construção da identidade do professor de língua. In: CORACINI, Maria José Rodrigues Faria; BERTOLDO, Ernesto Sérgio (Orgs.). O desejo da teoria e a contingência da prática. Discursos sobre-na sala de aula de língua materna e língua estrangeira. Campinas, SP: Mercados de Letras, p. 193-210, 2003.

HENRY, P. Sens, sujet, origine. In: DRLAV, Paris, 1981.

LAGAZZI, S. O recorte significante na memória. In: INDURSKY, F.; FERREIRA, M. C.; MITTMANN, S. (Orgs.). O discurso na contemporaneidade: materialidades e fronteiras. São Carlos: Claraluz, 2009, p. 67-78.

MOSTERÍN, J. Prólogo al libro de Estany A. Modelos de cambio científico. Barcelona: Editorial Crítica, 1990.

ORLANDI, E. P. Análise de Discurso - Princípios \& Procedimentos. Campinas, SP: Pontes, 1999.

ORLANDI, E. P. Identidade linguística escolar. In: SIGNORINI, Inês (Org.). Língua(gem) e identidade. Campinas, SP: Mercado de Letras, 1998.

ORLANDI, E. P. Discurso e texto: formulação e circulação dos sentidos. Campinas, SP: Pontes, 2001. 
ORLANDI, E. Recortar ou segmentar? In: Linguística: Questões e Controvérsias. Série Estudos. Uberaba: Faculdades Integradas de Uberaba, 1984. p. 09-26.

ORLANDI, E. P. A linguagem e seu funcionamento: as formas do discurso. $4^{\text {a }}$. ed., $2^{\text {a }}$. reimpressão. Campinas, SP: Pontes, 1983 [2001]. PECHEUX, M. O discurso: estrutura ou acontecimento. $2^{\mathrm{a}}$. ed. Trad. Eni Puccinelli Orlandi. Campinas, SP: Editora Pontes, 1983 [1990]. PEREZ, G. et al. Para uma imagem não deformada do trabalho científico. In: Ciência e Educação, v.7, n.2, p. 125-153, 2001.

SIQUEIRA, D. C. O. O cientista na animação televisiva: discurso, poder e representações sociais. Revista Em Questão, Porto Alegre, v. 12, n. 1, p. 131-148, jan./jun. 2006.

\section{Notas}

* Mestre e Doutora em Linguística Aplicada pela Universidade Estadual de Campinas (UNICAMP/DL/DLA/IEL). Docente da Universidade Federal de São Carlos (UFSCar).

** Graduando em Biologia da Conservação, da Universidade Federal de São Carlos, campus Lagoa do Sino.

${ }^{1}$ Mosterín (1990) afirma que a concepção empírico-indutivista da ciência afeta uma parte da comunidade científica. Essa ideia que atribui a atividade científica à experimentação, coincide, como bem observam Lakin e Wellington (1994), com a "descoberta" científica, veiculada, por exemplo, pelas histórias em quadrinhos, pelo cinema e pelos meios de comunicação em geral.

${ }^{2}$ Como já explicitamos, no caso do Professor Carvalho, a interlocução faz-se pela via do universo tecnológico, um telefone, uma tela de computador e sinal wifi. Quase ninguém tem acesso a seu laboratório - apenas Ash muito raramente -, o que, discursivamente, é bastante sintomático, uma vez que sinaliza o modo de representação imaginária construída para a ciência, o cientista e, por conseguinte, para o seu local de trabalho, o laboratório. 